\title{
Physical Education Implementation in Secondary Schools a Challenge to Teachers and Learners: A Case of Serenje District, Central Province- Zambia
}

\author{
Mwewa Maximo \\ Malcolm College of Education, Serenje, Zambia
}

\begin{abstract}
This study investigated what the Implementation of physical education brought to PE teachers and learners in secondary schools of Serenje district, Central province-Zambia. A case study design was adopted. The sample was chosen purposefully and consisted 110 respondents to which 32 were PE teachers, 6 Head teachers, 6 Heads of department for expressive Arts (PE) and 6 Heads of section for expressive Arts. Others were 60 pupils (30 boys and 30 girls) from secondary schools of Serenje district. The quantitative and qualitative designs were used to gather information from PE teachers, administrators and pupils. Semi-structured interviews and focus group discussions were the main research instruments. Data was gathered through focused group discussions for learners, while semistructured interviews were conducted for teachers and administrators. The Statistical Package for Social Science (SPSS-version16) was used to analyse quantitative data. The analysis involved frequencies and percentages of particular responses which were presented by using pie charts and barcharts. The qualitative data was analysed manually. The findings of the study were that; less PE time was allocated, use of PE class time for remedial work was dedicated to such subjects like Science, Mathematics and English, and there was generally negative attitude among other teachers and administrators towards PE subject. In this regard, PE teachers had to continually provide justification for the existence of their subject and plead for actual control of the time they were allocated.
\end{abstract}

Keywords: Physical Education, curriculum, Challenges, Secondary schools.

\section{Introduction}

The history of physical Education started around the $19^{\text {th }}$ century in the United States of America. This was because there was the growing popularity of formal physical education programs all over Europe, where calisthenics and gymnastics were common. American schools, therefore, opted to emulate the European model by incorporating physical Education into the curriculum for primary and secondary schools. These schools focused mainly on gymnastics, hygiene training and care, and the development of the human body. By the 1950s, over 400 institutes had introduced physical Education. However, physical Education became a formal requirement following the civil war when some states opted to pass laws that required schools to incorporate a substantial physical education component into their curriculums. Later in 1970, an amendment was made to the Federal Education Act that allowed women from high schools and colleges to compete in athletic competitions. This being the case, sex-based discrimination was completely outlawed from government funded programs [1].

During the late $20^{\text {th }}$ century, there was a decline in the commitment to physical Education. The growing tendency of offering extra subjects and electives in schools meant that the shift was focusing away from physical Education and towards academics. In addition, the United States of America also experienced a 
recession around the 1970s and 1980s, and this meant the decline in government funding of physical Education in secondary schools and Universities. However, the recent awareness of the need for balanced curriculums gave the national concern over the state of obesity, and children's attention towards non-physical activities like video games has brought physical Education back into the spotlight. The United States of America has re-signaled its commitment to physical Education by making it mandatory in public schools in early classes but making it an elective at the high school level. Therefore, it is undoubted that the history of physical Education in the United States was shaped by European influence [1].

In 2015, UNESCO affirmed that the offering of physical Education was declining all over the world, which increased the concern regarding public health. At this point in time, governments were encouraged to take a step in seeing that PE was included in the school curricula. Citing [2]'s statement, the World Health Organization stated that levels of physical inactiveness were rising, increasing the risk of diseases among people. WHO further explained that many people had no opportunities to do sport and exercise, and that made it even more important to value $\mathrm{PE}$ in schools, Considering the above situation, [2] recommended political measures to provide Quality Physical Education (QPE) which was defined according to the Association for Physical Education as planned, progressive, inclusive learning experience that formed part of the curriculum in early years, primary and secondary education, In this respect, QPE acts as the foundation for lifelong engagement in physical activity and sport. In addition, the learning experiences offered to children and young people through physical education lessons should be developmentally appropriate to help them acquire psychomotor skills, cognitive understanding, social and emotional skills they need to lead a physically active life.

In order to reach Quality Physical Education goals, UNESCO recommended policy actions to improve learning environments regarding adequate infrastructure, teacher education, curriculum flexibility, community partnerships and monitoring, and quality assurance. This being the case, public policies must ensure financial commitment to provide suitable space, facilities and equipment, and didactical resources that will foster students' learning. For example, adequate infrastructure in Brazil was perhaps one of the greatest challenges ahead. [3] stated that $15.5 \%$ of private and public Brazilian schools had appropriate and modern structures, $40 \%$ had the basic infrastructure, while $44.5 \%$ had minimum infrastructure that consisted only water, sewer, toilet, electricity, and kitchen.

In the context of precarious infrastructure, $\mathrm{PE}$ in schools had struggled over the years as it depended mainly on a variety of indoor and outdoor spaces. Therefore, the common challenges faced by PE teachers and learners in Brazil were a lack of appropriate space and didactical resources.

In Africa, physical Education was grounded in traditional Education, wherein physical prowess was highly revered. This is because Africa has a rich tradition of culture, history, sport, and social institutions. The rich traditional games, plays, dances, and arts of the continent have stood the test of time. Therefore, the practice of physical Education is deeply rooted in the cultural fabric of various ethnic communities who developed physical prowess as an integral part of the traditional process associated with practices of food gathering, pastoral activities, and inter-tribal conflicts. These historical practices mark the first phase in the evolution of Physical Education in Africa. The second phase is characterized by contact with the western world, which marked the beginning of the reduction in traditional Education and the establishment of colonial/ missionary models of Education. These models of Education regarded indigenous physical activities as primitive, immoral, and antiChristianity. This being the case, the colonial masters formalized physical Education and sport 
into military drills, physical training, and the training of teachers. As various western powers colonized many African countries, a number of Physical Education syllabi, which emphasized the above skills, were then introduced to various African countries. For example, in 1933, Britain introduced a physical education syllabus to all its colonies that had no cultural values to the Africans. In the third phase, most African countries attained their independence and then tried by all means to restore the dignities and values of physical Education that were done away during the colonial times. The postindependence period and the last decade of the $20^{\text {th }}$ century marked the fourth phase in the evolution of physical Education and sport. However, PE experienced major setbacks because of the prevailing socio-economic challenges around the world. Several PE and Sport programmed collapsed due to a lack of funding [4]. In Nigeria, PE is taught and is examinable; in Uganda, it is timetabled but not seriously taught, whereas in South Africa, PE as a school subject no longer existed, but taught indirectly as a small component of the learning area- Life Orientation, along with health promotion, personal and social development, and orientation to the world of work foci in grades 8-9 [5]. Shortage of facilities is widely reported throughout the African continent.

The above statement is supported by [6] when he stated that PE continued to be a marginalized subject in school curricula worldwide. In an international survey that investigated other African nations, he discovered that the status of PE was low, and the subject was in danger of being sidelined. This scenario brings a challenge to both PE teachers and learners when conducting physical education lessons.

In Zambia, the history of physical Education can be divided into the indigenous period, the colonial period, and the post-independence period. Physical Education was essential and utilitarian in the indigenous period because it was simply part of the lives of the people at that time. People walked, swam, ran, and were involved in many other forms of physical activity. Physical Education was indispensable. Later, the missionaries provided Education to the Africans for the purpose of transmitting the Good News. However, such an attempt rid the Africans of their culture. As the missionary form of Education grew, many subjects- including PE, were added to the curriculum. However, while many subjects have enjoyed great popularity in the Zambia School Curriculum, physical Education has suffered marginalization, so are the PE teachers and the learners. The subject (PE) was not examined in schools but only in teacher training colleges and the University of Zambia [7].

[4] stated that the late president Mwanawasa declared PE to be taught in all schools in the year 2005. This was followed by a Circular minute No. 1 of 2006. The above statement is supported [8] when he said that, 'to show the importance of $\mathrm{PE}$, the former President- Mwanawasa gave a directive to the Ministry of Education in 2005 so that it could be taught in all schools across the country. PE as a subject was then introduced to the primary school examination as part of Creative and Technology Studies (CTS) and most recently as Expressive Arts (EA). PE is now examined at both junior and senior secondary levels. Despite such positive development, PE teachers and learners still experienced challenges in performing the art, hence the urgency for having undertaken this study.

\section{Statements of the Problem}

PE has developed from simple drills to varied patterns of activities aimed at improving the physical well-being of individuals and communities. PE improves the general health of the individual, creates the love for sports and games, serves as the basis for training of potential athletes for the clubs and nation, and imparts a health and positive attitude of mind that helps academic work in schools. PE offers such elements and affords learners a chance to 
play and to socialize as they participate in physical activities [9].

Further, the physical education curriculum has special importance in secondary schools because it prepares learners in the areas of physiological, physical, and skills training in order for them to achieve a healthy and sustainable life. In addition, Physical Education does increase students' enjoyment, confidence, and competence in a range of physical activities. Students could also learn health-related fitness and be able to take responsibility for being physically active for now and in the future [10]. It was for the above reasons that, in 2005, president Mwanawasa declared PE to be compulsory in schools. This being the case, the recognition of practical subjects in Zambian secondary Schools' Curriculum made physical Education to be an examinable subject [11]. Despite the Government's directive in ensuring that the teaching of PE in Zambian secondary schools was compulsory and examinable, the challenges in participation among secondary schools remain below national recommendations. Therefore, PE and Sports as a field of inquiry in Zambia is greatly characterized by neglect than by attention [12] In this regard, the researcher embarked on a study to ascertain the challenges faced by $\mathrm{PE}$ teachers and learners in secondary schools of the Serenje district. The previous studies on PE dwelt much on the Implementation, and the subject's being examined in secondary schools. However, the knowledge Gap in this study was the challenges PE teachers and learners faced in conducting the art, bearing in mind that the subject was now being examined in those secondary schools.

\section{Research Methodology \\ Instruments for Data Collection}

To achieve the objectives of this study, the researcher mainly used semi-structured interviews schedule and Focused Group Discussion Schedules, respectively.
The semi-structured interview schedule and Focus Group Discussion Questions were selfdesigned. A semi-structured interview is a qualitative method of inquiry that combines a pre-determined set of open questions (questions that prompt discussions) with the opportunity for the researcher to explore particular themes or responses further [13]. A semi-structured interview does not limit respondents to a set of pre-determined answers (unlike a structured questionnaire). Semi-structured interviews allowed respondents to discuss and raise issues that the researcher never considered, thereby allowing capturing in-depth data. Semistructured interviews are often preceded by observation, informal and unstructured discussion in order to allow the researcher to develop a keen understanding of the topic of interest. On the other hand, Focused Group Discussion (FGD) was conducted among the learners. FGD is a form of qualitative research methodology in which a group of learners was asked about challenges they faced in learning PE.

Data on the documents were skillfully analyzed in order to verify the information collected from the interviews. Focus group discussions and interviews were carried out in all schools which offered PE. The researcher also used simple observations of respondents' nonverbal cues during interviews and the surroundings in order to confirm whether some of the issues they claimed to have been happening were true.

\section{Validation of Data Collection Instruments}

The semi-structured interview schedule and Focus Group Discussion Questions were selfdesigned. The two instruments for data collection were submitted to the experts at Nkuruma University, who determined their face and content validity. The three experts who moderated the research instruments before the researcher launched them on a full-scale investigation belonged to the department of Expressive Arts at Nkuruma University. 


\section{Qualifications of Teachers}

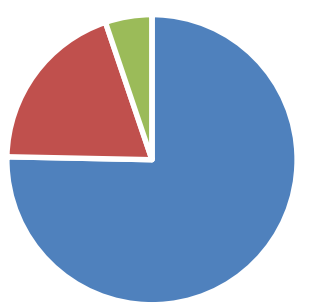

- Certificate - Diploma - Degree

Figure 1. Qualification of PE teachers in Secondary Schools

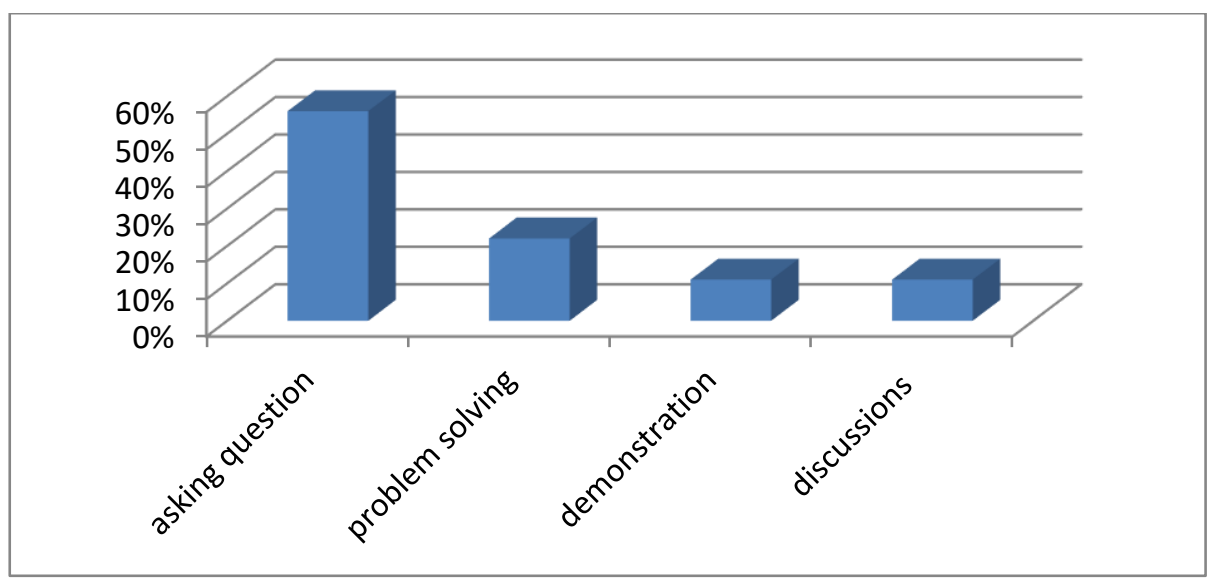

Figure 2. Learning Activities used in Teaching PE

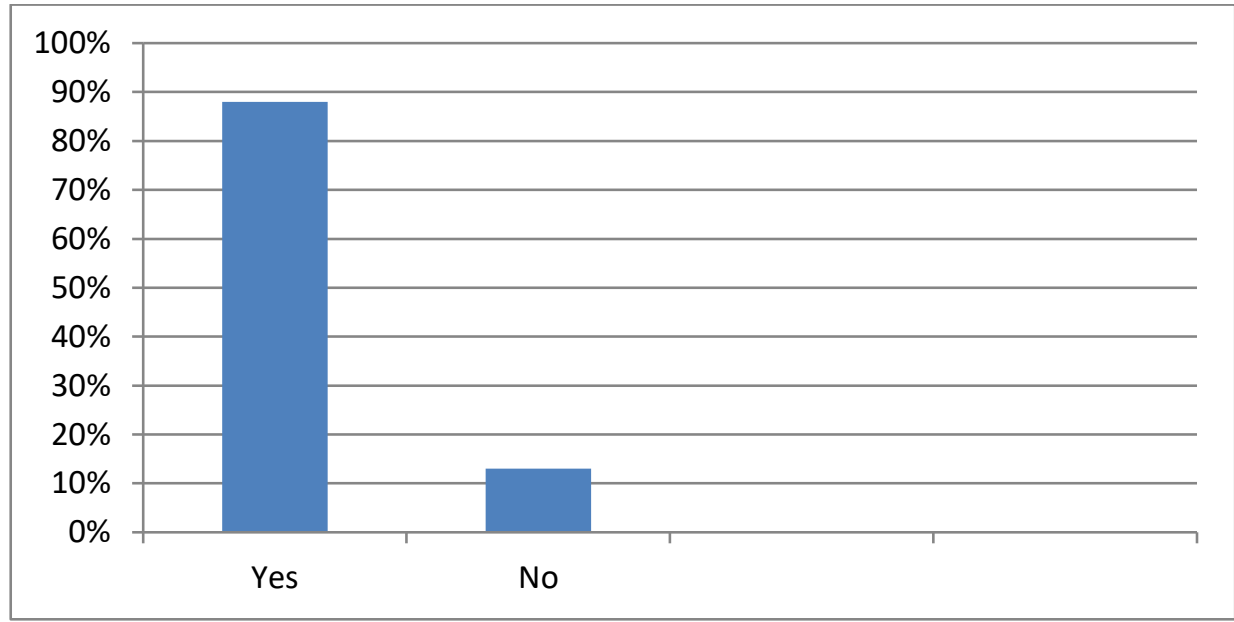

Figure 3. Teachers' Responses on use of Trigonometry Teaching Resources 


\section{PE equipment \& facilities}

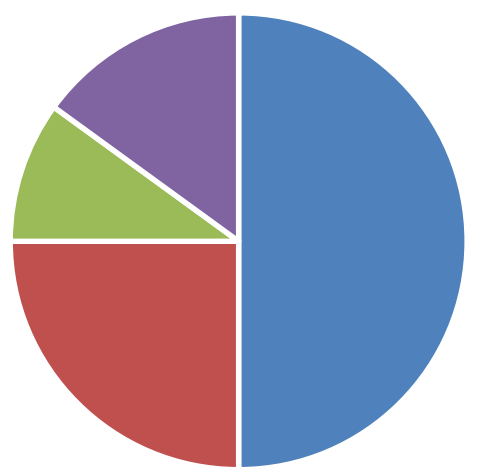

- Fied events - Gymnastics $\quad$ Basketball courts - Recreation halls

Figure 4. The Availability of PE Equipment and Facilities

Challenges faced when teaching PE in secondary schools

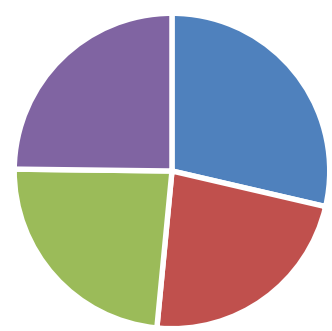

- Poor Playgrounds

- poor T/L Aids

- Non-availability PE infrastructure - Lack of PE equipment

Figure 5. Challenges Faced when Teaching PE in Secondary Schools

\section{Conduct of PE practical in schools}

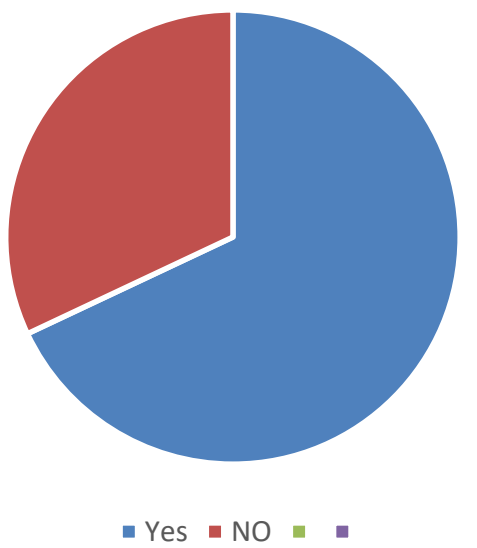

Figure 6. The Availability of Space to Conduct PE Practical 


\section{Discussion of Findings}

This chapter presented the study's findings according to the research questions on the challenges faced by PE teachers and learners in secondary schools of Serenje district.

\section{Result and Discussion}

\section{Semi-Structured Interviews for Teachers and Administrators}

The Findings of the study were that the Serenje district had 93 schools that offered grades 8 to 9 . However, it was learned that out of 93 basic schools, there were only 13 schools that offered PE, representing 14\%. At the senior level, out of the 15 secondary schools in the district, only five (5) were offering PE, representing $33.3 \%$.

The study further revealed that despite many schools not offering PE, there were many trained and qualified teachers of PE in the Serenje district. The non-practicing by the trained $\mathrm{PE}$ teachers was also regarded as a challenge to the learners because they could not benefit from the physical education skills. According to the qualification audit conducted by the district education office, it was found that 250 teachers were trained in PE out of a total of 1060. This figure represents a percentage of $23.6 \%$. The levels of training valid from certificate, diploma, to degree. It was equally found out by the researcher that the majority of the trained teachers in PE had certificates. This entails that many teachers needed to up-grade to diploma and degree programs.

Question 4 sought to investigate learning activities used by teachers when teaching PE in secondary schools. The results showed that the majority of teachers used questioning techniques (60\%), followed by solving problems $(20 \%)$. Demonstration and discussion methods were both at $10 \%$, indicating that $\mathrm{PE}$ teachers minimally utilized them. In turn, the learners never benefited much from demonstration and discussion methods due to the under the utilization of such methods by the PE teachers.
Question five dealt with the availability of PE equipment and facilities in secondary schools. The study's findings showed that equipment for the field events was available at $50 \%$, followed by gymnastics equipment at $25 \%$. The recreation halls $(15 \%)$ and basketball courts $(10 \%)$ showed the poor state in which the two facilities were. This is a great challenge on the part of PE teachers and learners because the subject will be performed with difficulties and less interest between the two parties.

Concerning question six, the study revealed that teachers faced numerous challenges that demanded immediate attention from stakeholders such as school administrators, parents, civic leaders, and the government. Areas of concern included: the poor state of facilities like; the playgrounds, teaching and learning materials, poor state of Infrastructure, and generally lack of equipment, as well as acute shortage of PE facilities and insufficient time allocation. The study also indicated that Local communities had equally contributed to the vandalism of the few $P E$ facilities in the secondary schools under study. For instance, local people had made roads and footpaths on the playing fields, hence making them unconducive for games and athletics. Apart from that, theft of sports equipment has had a negative impact on the teaching of PE in these secondary schools. It was also discovered by the researcher that most of the goalposts on football, netball, and volleyball playing grounds were stolen, especially in urban schools. Balls and football boots were equally stolen by pupils in both rural and urban secondary schools. This is the more reason why some headteachers decided not to support Physical Education in their schools. The study also revealed that some administrators had a negative attitude towards the subject (PE) as they regarded that offering it was a sheer waste of time when compared to Science, English, and mathematics, despite the subject being examined.

With regard to the spaces for $\mathrm{PE}$, it was possible to identify differences between 
secondary schools because some of them had suitable dimensions for physical practical, while others had none. The criticism expressed by some respondents, for example, referred to the size of the playgrounds that were insufficient (32\%), while other respondents (68\%) stated that they had enough space to conduct PE practicals. Therefore, the findings of the study were that many schools had enough space to conduct PE practical, but the only challenge was that those spaces were not landscaped. These uneven fields paused a danger to the PE teachers and learners in terms of accidents.

\section{Focus Group Discussions.}

Question one investigated whether the learners were interested in Physical Education or not. Many respondents stated that they were interested in PE, while few respondents said that they were not. Therefore, the higher figure indicated that Students were generally interested in PE. The few who were not interested in physical Education stated that some teachers discouraged them because the subject was just optional.

Concerning the number of times PE periods occurred during the week, students stated that it appeared twice on the timetable. The findings of the study were in line with a study conducted by [14] on the role of PE in the total development of the child, which revealed that time was a scarce resource in many schools, and teachers of different subjects competed for that resource. [15] also indicated that the way PE was timetabled affected the learning of pupils. Other literature showed that PE was easily overlooked in many secondary schools because they adhered to a rigid timetable where the subject was expected to be taught by a specialist teacher. The literature further showed that, despite $\mathrm{PE}$ and Sports' cultural and educational significance as a field of inquiry in Zambia, it was characterized more by neglect than by attention [12].

The common material resources used in teaching and learning were charts and textbooks. The respondents stated that the learning and teaching resources were there, though not enough (especially textbooks). The charts were also very old and needed replacement. This was a great challenge on the part of the learners because one book had to be shared amongst four pupils in case of homework.

Generally, the playing fields were not conducive for PE activities due to nonmaintenance by the schools. Some portions of the playgrounds were half slashed, while other parts had uneven grounds and un-slashed shrubs. This showed the unwillingness among the PE teachers to take up their responsibilities in making the subject more recognized. Such playing fields became a challenge to learners as some PE practical required learners to have enough space in order to perform them.

Concerning challenges faced by students during PE practical, the respondents stated the following: time allocated was not enough, teachers were not prepared to perform physical activities, and lacked equipment and facilities to use. The above challenges clearly indicated that PE had a long way to be fully implemented in Zambian secondary schools. Nyawali supports the above statement by [16] when he postulated that lack of teaching aids, equipment, and facilities for PE in secondary schools could reduce pupils' participation in the subject.

Concerning the recognition of PE subjects by other teachers in the school, the respondents stated that many teachers discouraged them to concentrate on it. They said that it was a sheer waste of time since there were no jobs that required them to pass $\mathrm{PE}$. Such negative utterances show the slow recognition of PE subject among the elite, despite its being examined in secondary schools. The above statement is supported by [17] when he observed that making PE another academic subject would create problems of another kind as it must retain its aspect of enjoyment. Basing on [17]'s statement, it can be deduced that $\mathrm{PE}$ is perceived for fun and enjoyment only. This was a challenge to both the PE teachers and learners. 
Many respondents stated that the administrators were supposed to take responsibility of making sure that PE was taught in those secondary schools, like any other subject. The purchasing of equipment and teaching/learning materials and the building of recreation halls were equally mentioned as the contributor towards the implementation of PE in secondary schools. In addition, negative remarks came from teachers with negative attitudes and who felt PE should be replaced by core subjects like Science, Mathematics, and English. The analysis of these results was that, despite teachers seeing the importance of learners' participation in PE for mental and physical health, PE seemed to them as a mere recreational programme for leisure, hence the challenge to PE teachers and learners. If not attended to, the things as mentioned above will continue affecting the running of PE in secondary schools.

\section{Conclusions and Recommendation}

\section{Conclusion}

The study revealed that the physical Education and sports curriculum in secondary schools of the Serenje district were not conducted as per the Ministry of Education's expectation. The study concluded that, despite Government making PE examinable in Zambian secondary schools, the subject continued suffering from non-recognition compared to other subjects. Therefore, PE has been neglected, looked down upon, and regarded as a time for learners to play and have fun only. In some secondary schools, PE was viewed as a play or sport that took away time from academic subjects. Other administrators cited lack of equipment and facilities as major reasons why they did not offer Physical Education in their schools. The administrators lamented that PE facilities like basketball courts, recreation halls for indoor games, equipment for field events in athletics and gymnastics were very expensive to construct or purchase. The findings of the study concluded that the implementation of $\mathrm{PE}$ in secondary schools of serenje district was low mainly due to the high prices of equipment, attitude of administrators towards the subject, and the non-availability of recreation halls. It was also found that PE teachers and learners equally faced challenges in PE equipment, resources, and facilities.

\section{Recommendations}

In view of the results obtained from the study and other findings during data collection, the following recommendations were made

1) Government to sensitize secondary school administrators through the office of the District Education Board Secretaries (DEBS) over the importance of PE to the learners.

2) Government and Secondary Schools should find money to buy PE facilities, equipment and build PE facilities in secondary school. This positive move will reduce challenges currently being faced by PE teachers and pupils in conducting physical Education practical in Zambian Secondary Schools.

\section{Conflict of Interest}

Author declares there is no conflict of interest.

\section{Acknowledgement}

I would like to thank my supervisor Dr. Sichanga and Dr Sikwela who tireless guided me throughout the compilation of this dissertation.

I would also like to show my appreciation to all lecturers in the department of Expressive Arts at the university of Zambia for their contribution and support towards the success of this dissertation. I would equally like to thank all the respondents who i came into contact with, for their cooperation during data collection. They really helped me to accomplish the intended task.

My special appreciation also goes to brother Mwewa, my wife and other family members for their endless financial and moral support. I equally thank all colleagues who never ceased to encourage me in my studies. God bless you all. 


\section{References}

[1] Amusa, L.O. and Toriola, A. L., (2010). African Journal for Physical Activity and Health Sciences Vol. 16. No. 4.

[2] UNESCO (2015). Global Survey of the Status of Physical Education. Paris: UNESCO.

[3] Neto JJS, Jesus GR, Karino CA, Andrade DF. (2013). A scale to measure school infrastructure. East. aval. Education.

[4] Mubita, A. (2017). A History of Physical Education in Zambia. Lusaka: Unza Press.

[5] Hardman, K. (2000). Physical Education and Sports: An Occupational Perspective $\left(9^{\text {th }}\right.$ ed). London: Mosby Company.

[6] Hardman, K. (2008). Physical Education in schools: A global perspective. Kinesiology, 40 (1): 5 28.

[7] Mwanakatwe, J.M. (2013). The Growth of Education since independence. Lusaka: University of Zambia Press.

[8] Njelesani, J. (2012). Examining Sport- forDevelopment using a critical occupational Approach to Research. Toronto; University of Toronto.

[9] Vannier, M., Foster, M., and Gallahue, D. L. (2010). Teaching Physical Education in elementary schools. Philadelphia.; Saunders Publishers. [10] Bucher, C.A. (2010). Administration of Physical Education and Athletic Programme. St. Louis: The Mosby Company.

[11] Moesvtee (2013). Zambia Education Curriculum Framework. Lusaka: CDC

[12] Mutiti, M. 2011. Factors contributing to the Poor Status of PE in selected schools of Chongwe District. Lusaka: Unza Press.

[13]Bryman, A. (2008). Social Research Method. New York: Oxford University.

[14] Ogundare, O.A. (2000). The Role of PE in the Total Development of the Child.

[15] Green, K. (2003). Physical education teachers on physical Education: A sociological Study of Philosophies and ideologies. London: Chester's academics.

[16] Nyawali, L. (2003). Implementation of physical education in secondary schools. SAGE.

[17] Green, K. (2003). Physical Education Teachers on Physical Education; A Sociological Study of Philosophies and Ideologies. London; University of Chester. 